\title{
Colorectal Cancer: A Study of 206 Malignant Cases
}

\author{
Y. Subrahmanyam ${ }^{1}$, K. Suneetha ${ }^{2}$ \\ ${ }^{1}$ Department of Pathology, Affiliated to Rajiv Gandhi Institute of Medical Sciences (RIMS), Ongole, A.P., India \\ ${ }^{2}$ Department of Pathology, RIMS, Ongole, A.P., India
}

\begin{abstract}
Background: Carcinoma of colon and rectum is one of the most common malignancies in the world and its incidence is rising in the countries that are adopting western life styles (1). The cause and pathogenesis of colorectal carcinoma are related to both environmental and genetic factors (2). There is a close relation between meat consumption and incidence of large bowel cancer (3). Other foods particularly vegetable fibre may be protective, Buskitt DP 1971. Genetic factors play a role possibly governing a proneness to adenoma development (4). Cancer is age related, the increasing age increase incidence, in high risk areas approximately 8\% of patients under the age of 50 years (5). A proportion of carcinomas arise within pre existing adenomas (6). Objective is to study the occurrence and Clinical pathological correlation of malignant tumours of colorectum. The methodology is retrospective four and prospective four years study of large intestine malignancies from 2007-2015. Results: 206 (21.28\%) cases of colorectal malignancies out of 968 GIT malignancies with a peak in the 41-60 age groups. The male to female distribution ratio was 2:1. Conclusion: Adenocarcinoma was the most common type of presentation $86.89 \%$ (179) of all large bowel malignancies.
\end{abstract}

Keywords: colorectum, adenocarcinoma, carcinoid, lymphoma, GIST

\section{Review of Literature}

\section{Introduction}

Cancer of the colon and rectum is one of the most common forms of malignant disease in north -west Europe, North America and Australia, the incidence is rising in countries that are adopting western life styles (1). The cause and pathogenesis of colorectal carcinoma are related to both environmental and genetic factors (2). There is a close relation between meat consumption and incidence of large bowel cancer (3). Other foods notably vegetable fiber may be protective Buskitt DP, 1971. Genetic factors play a role possibly governing a proneness to a adenoma development (4). Cancer is age related, the increasing age increase incidence, in high risk areas approximately $8 \%$ of patients under the age of 50 years (5). A proportion of carcinomas arise within pre existing adenomas (6). Cancer rise within a back ground of familial adenomatous polyposis, chronic inflammatory bowel disease including ulcerative colitis, Riddell RH et al 1983, schistosomiasis, Ming-cheri C et al 1980 and chrohn's disease, Hamiltan SR 1985. Juvenile polyposis, Jass JR et al 1988 and following pelvic irradiation , Qizilbash AH 1974. The distribution of adenocarcinomas $65 \%$ in the rectosigmoid region $5 \%$ in the rectum and remainder equal in the remainder colon, Welch CE 1957. In the series of Welon and Bruke1962 about 15\% arise in the caecum ands ascending colon, $2 \%$ in hepatic flexure, $5 \%$ in the transverse, $3 \%$ in the splenic flexure $10 \%$ in the descending colon and the remainder in the sigmoid colon and rectum. Recent epidemiological evidence suggests that the development of colonic cancer may be related to the spread or passage of material through the gut and to the presence and type of bacteria in the lumen of the intestine (7). Carcinoma of the colon and rectum is disease of middle and later life with a mean incidence towards the end of sixth decade and affects males twice as often as females. Cancers proximal to the rectum tend to develop more commonly in females, Berk and Hanbrick 1963, although in later life the incidence in men is higher than in women, Ashely 1970. The carcinomas of the large bowel in advanced stage may present with rectal bleeding, changes in bowel habits, anaemia and intestinal obstruction. Many attempts have been made to detect the colorectal cancer at an earlier stage (8). Procto-sigmoidoscopy and biopsy for both men and women after 40 years detect approximately $50 \%$ of cases (9). Grossly colorectal carcinomas can be described as either polypoid or ulcerative/infiltrating (10).

Adenocarcinoma the usual malignant tumour of the large bowel is a well to moderately differentiated adenocarcinoma secreting visible amounts of mucin. The tumour cells represent a combination of columnar and goblet cells with occasional participation of endocrine cells and exceptional occurrence of paneth cells (11). The carcinoma consistently elicits an inflammatory and desmoplastic reaction which is particularly prominent at the edge of the tumour. Most of the inflammatory cells are T-lymphocytes, Horny HP et al 1987. But B-lymphocytes, plasma cells, histiocytes and S 100 protein-positive dendritic cells may also be present, Ambe K et al 1989. The tumour may be seen invading all the layers of the bowel and extending into the peri colic fat, permeating peri neural space and invading veins which is of prognostic significance, Belhis D et al 1953. Rarely the tumour stroma may exhibit metaplastic bone formation, Buker CE, 1939. Histochemically, the large majority of colorectal carcinomas are positive for mucin stains, Culling et al 1975. Ultra-structurally a constant feature of colorectal carcinoma is the presence of prominent collections of microfilaments running perpendicular to the cell membrane and entering the brush border, Hickey WF et al 1981. The p53 mutations have been detected by molecular technique in the majority of colorectal carcinomas (12). Mucinous adenocarcinoma is a special type of colorectal carcinoma in which large lakes of extracellular mucin are formed, mixed with collections of tumour cells, Sasaki O et al 1987. By definition the mucinous foci should constitute at least half of the tumour mass, Connelly JH et al 1991. Mucinous tumours comprise $15 \%$ of colorectal carcinomas and occur most commonly in the rectum. In a series of 132 cases reported by Symonds and Vickery 1976, 31\% were associated with bullous adenomas, $7 \%$ with ulcerative colitis, $8 \%$ with 


\section{International Journal of Science and Research (IJSR) \\ ISSN (Online): 2319-7064 \\ Index Copernicus Value (2013): 6.14 | Impact Factor (2015): 6.391}

colitis and 5\% with prior pelvic irradiation. Mucinous carcinomas are also more frequently associated with adenoma elsewhere in the colorectum than are conventional adenocarcinomas, Sunblad AS et al 1982 and tend to present at a more advanced stage, Youners $M$ et al 1993. The prognosis is somewhat worse than the conventional type of adenocarcinoma at least when they are located in the rectum and/or if they are stage B lesions, Sadahiro O et al 1989, Connely KH et al 1991, Gren JB et al 1993. Signet ring carcinoma is a rare form of colorectal malignancy that usually affects young patients like its more common gastric counterpart. It usually presents grossly as a diffuse infiltration of the wall Giacchero A et al 1985, Laufman H et al 1951. Metastases tend to develop in lymph nodes, the peritoneal surface and the ovary rather than the liver. Pattern of spread is mainly in the form of peritoneal dissemination and the prognosis is extremely poor, Basthazar EJ et al 1979, Nakahat AH et al 1992. Adenosquamous carcinoma is more common in caecal neoplasm that may be seen in any areas of the large bowel, Crissmars JD et al 1978, Home BD et al 1978. Thomas P Conner 1971, reported eight cases of primary squamous cell carcinomas of rectum and colon. It has been postulated that some of these squamous tumours may arise from areas of squamous differentiation in preexisting adenomatous polyps, William GT et al 1979. The prognosis depends largely on the stage of the disease as determined by depth of invasion and regional node involvement, Boman BM et al 1984 \& Doughenty BG et al 1985. Involvement of inquinal lymph nodes is an extremely grave prognostic sign $(13,14)$. In the series of Pan Morsan 1967 , the 5 year survival rate was $90 \%, 60 \%$ and $0 \%$ for well differentiated, moderate and poorly differentiated tumours respectively.

Small cell carcinoma is a highly undifferentiated neoplasm formed by large solid nests of small hyper chromatic cells with central necrosis. These lesions have been found to have signs of neuroendocrine differentiation, ultra structurally and immuno histochemically, Wick MR et al 1987. Cases of this tumour type have been reported in HIV infected patients, Nakahara $\mathrm{H}$ et al 1993. Spindle cell (sarcomatoid) carcinoma is not as common as in the upper digestive tract but it does occur, Kalogeropoulos NK et al 1985. Cases have been reported of anorectal adenocarcinomas containing abundant melanin pigment in the cytoplasm of the tumour cells, Chumors IC et al 1981.

Malignant melanoma approximately one melanoma is seen for every 8 squamous cell carcinomas and one for every 250 adenocarcinomas of the anorectal region (15). Rectal bleeding is the most common complaint. The typical gross appearance is that of single or multiple polypoid masses covered by a smooth surface. Microscopically, these tumours are usually melanotic and two thirds show a junction component with lentiginous appearance in the adjacent mucosa, Wanbo $\mathrm{HJ}$ et al 1981. The tumour is occasionally of the desmoplastic variety, Ackerman DM et al 1985. The overall prognosis, which in general is extremely poor, is directly related to the tumours size and depth of invasion, Mills SE et al 1953, Wanebo JH et al 1981, Antonick PM et al 1983.
Lymphomas: Are less frequently found in the large bowel than in the small bowel or stomach. Some of these cases of large bowel lymphomas have been seen in renal transplant recipients or in patients with ulcerative colitis, GS et al 1974; Reuton P et al 1982; Greenstain AJ et al 1992. These tumours can occur at any level of colorectum, Vander Heule B et al 1982, Hang WS et al 1992. The regional lymph nodes are involved in about half of the cases. Colorectal malignant lymphomas are nearly always of non Hodgkin's type (16). Other reported types of colorectal malignancies include mantle cell lymphoma, Mc Culbugh JE et al 1992.

The large bowel GISTs are rare (17). In a review of 56 GISTS by Markku Meittinen 1987, not a single case was reported in the large bowel. In a study of 27 cases, only GIST was reported in the rectum, Lina Wang-Human Vaugas Samuel W French, 2000.

Large bowel carcinoids are more common in the rectum, Horn RC Jr 1949, Donald H Kupier et al 1970. Of the 147 cases of rectal carcinoids examined by Caladarola et al 1964 , 105 measured less than $0.5 \mathrm{~cm}$ in diameter, only three were associated with lymphnode metastasis and all of these were larger than $2 \mathrm{~cm}$ in diameter. Rectal carcinoids have been reported in bowels affected by ulcerative colitis , Gledmill A et al 1986 or Crohn's disease (18). They have also been reported in association with ovarian carcinoid,Williams RM 1979. Grossly one of its most distant features is the yellow colour that it acquires after formalin fixation. Argentaffin and Argyrophil reactions are said to be usually negative, Block WC, 1968. But consistently positive results with the use of the Grimelius stain have been reported by several authors, Hosoda J, 1975, Schimoda T et al 1984, Burke AP et al 1990. Rectal carcinoids have also often been found to exhibit immunoreactivity of CEA (19), HCG, Fukayama M et al 1987 and prostatic acid phosphatise (20). Immunochistochemical studies of GIT carcinoids show that majority is multi hormonal and somatostatin is the commonest tumour marker, Prathiba et al 1990. Most of the GIT carcinoids are positive to NSE, Chromograffin A and PGP 9.5 (21).

\section{Observations}

Total number of surgical specimens 23717. Total number of body malignant lesions observed 4846. Total number of GIT lesions observed 2868. Total number of GIT malignancies noted 968.The malignancy of large intestine in the present study was (206) $21.28 \%$ of all GIT malignancies. Caecum 14 cases $2.2 \%$, colon 75 cases $11.8 \%$, rectum 117 cases $18.35 \%$. Majority of the cases fell within the age group of 31-70 with a peak in the 41-60. The male to female distribution was 139 cases to 67 cases resulting in the ratio of $2: 1$. In the caecum and colon, majority of cases were males, whereas females almost equalled males in the rectal cancers-table 2.

All large intestine tumours presented either with rectal bleeding, changes in bowel habits, anaemia, vague abdominal pain, intestinal obstruction, mass per abdomen. Most of the patients suffered with all or one of the above symptoms with an average 3-6 months duration before diagnosis. Most of the large bowel lesions had a gross 


\section{International Journal of Science and Research (IJSR) \\ ISSN (Online): 2319-7064 \\ Index Copernicus Value (2013): 6.14 | Impact Factor (2015): 6.391}

appearance of polypoid, ulcerative and infiltrative type. The polypoid type presented as bulky mass with well defined rolled margins and sharp dividing line with a normal bowel. The ulcerative infiltrating tumours had a less elevated surface and were centrally ulcerated. On cross section greyish white tissue was seen replacing bowel wall. Some of the tumours showed gelatinous and glaring appearance. All the large intestinal malignancies were classified histopathology using WHO classification for large intestine malignancies. Adenocarcinomas were the most common type of presentations. 11 cases in the Caecum, 67 cases in the Colon, 101 cases in the rectum were reported comprising $86.89 \%$ of all large bowel malignancies. This is followed by $9(4.36 \%)$ cases of caracinoid, $5(2.43 \%)$ cases of GIST, lymphoma $3(1.45 \%)$ cases and Melano carcinoma 3 $(1.45 \%)$ cases.

The carcinoid grossly presented as firm greyish white well circumscribed tumours with characteristic yellow coloration after formalin fixation fig.3. Microscopically the classic insular and tubular types are observed followed by solidness of small monotonous cells with occasional acinar or rosette formation fig.6. Adenocaracinomas were diagnosed by the presence of intestinal type of glands lined by columnar and goblet cells with pleomorphic and hyper chromatic nuclei with inflammatory and desmoplastic reaction. The tumour showed well to moderately differentiated cells fig 19\&20 or glands infiltrating in the muscular layers and serosal layers. Some of the tumours showed variable amount of mucin secretion. Those tumours showing more than $50 \%$ of mucin were diagnosed as mucoid adenocarcinomas fig. 5 and more than $50 \%$ showing signet ring cells as signet ring adenocarcinoma. One adenocarcinoma with neuroendocrine differentiation was noted in the caecum and ascending colon. The patient presented with pain abdomen associated with vomiting since 15 days. On gross examination, the polypoid mass of $6 \mathrm{~cm}$ diameter with serosal small tubercle like lesion noted. Histopathology of the tumour was composed of nests of medium size uniform round cells predominantly occupying as sub mucosal region and cords of similar cells infiltrating the wall transmurally with abundant extracellular mucin, the overlying mucosa normal. Immunohistochemistry was done. Chromogranin and syaptophycin were negative, CEA positive. A final diagnosis of mucin producing adenocarcinoma with neuroendocrine differentiation was made. 5 cases of GISTS reported in rectum. The tumour was presented with pain and bleeding per abdomen. Grossly the tumour was $14 \times 5 \times 3 \mathrm{~cm}$ in the rectum. The tumour was a lobulated mass of $6 \times 7 \mathrm{~cm}$. The cut section showed grey white with haemorrhage and necrotic areas. Microscopically highly cellular mass arising from sub mucosa composed of long spindle cells with elongated nuclei with esinophilic cytoplasm with prominent nucleoli and mitotic figures, arranged in fassicles with intervening of collagen and areas of hemorrhage and necrosis, in focal areas the tumour was appeared to be extending up to the overlying lamina propria. GIST in the rectum showed neural differentiation, s100 positive, vimentin focally positive, desmin and actin negative. 2 cases of squamous cell carcinoma were noticed, one from rectum and one from anal canal. Histopathology showed well differentiated, moderate and poorly differentiated. In well differentiated more than $75 \%$ epithelial pearls noted, whereas in moderately differentiated carcinoma $<50 \%$ keratin pearls, in poorly differentiated no epithelial pearls. The cells show small hyper chromatic nuclei less differentiation arranged in sheets. The tumour grossly presented as ulcerating growth with rolled out edges. Histology of the basal cell carcinoma composed of solid sheets of small cells with peripheral palisading and foci of mucin and areas of squamous differentiation. Some of the tumours showed conspicuous mitotic activity. The malignancies showing mucin production were subjected to PAS and mucicarmine special stains. PAS stain shows the mucin secreted by the malignancies appeared as magenta red colour fig5. Melanocarcinomas of colon three cases noted fig.4\&fig7.

\section{Discussion}

The malignancy of large intestine in the present study was $21.28 \%$ (206cases) of all G.I.T., malignancies and $4.25 \%$ of all malignant lesions of the body. The number of cases observed 206. 14 (6.80\%) cases caecum, 75 (36.40\%) cases colon, 117 (56.80\%) cases rectum, table3. It is well recognised fact that in developed counties cancer of the colon-rectum is more prevalent than in under developed counties. Countries with a high rate of cancer of the colon have a relatively high rate of cancer of rectum. An exception to this is Japan where colon cancer is significantly less common, but rectal cancer is as common as in United States (22). Highest incidence of rectal and colon malignancies are from USA followed by UK and Norway. Jussawala (23) observed an incidence of $34 \%$ for large intestine malignancies from whole of India which is higher than that observed in the present study. Other reports of higher incidence are from Pay Master (24) from Agra 60.45\%, Pay master from Hyderabad $60.69 \%$ and Khodeskar from Nagpur $75.22 \%$.

In the present study, the highest frequency for cancer colon and rectum was found to occur in the age group of 31-70 years $84.95 \%$ table 2 . This age wise frequency is in line with that observed in western countries. Nadler et al 1963 have recorded the highest incidence in the age group of 60-79 years. Golighan 1975 analysing 1063 cases of carcinoma of rectum found the highest incidence in 60-69 years group. In the present study the peak incidence was observed in 41-50 years group followed by 51-60 years table16. The youngest in our group was 17 years old male. In this case, histology of the tumour mimicked mucinous type of carcinoid and with the help of IHC the final diagnosis of adenocarcinoma was made. The oldest was 82 year old male. The sex wise distribution in the present series was 2:1 male to female ratio. This corresponds with the observation of Leena Devi and Suvarna et al, 1.85:1 and Goligher 2:1. Carcinomas in the sigmoid and recto-sigmoid regions are more frequent in western countries which are a reflection of their high incidence of colon cancers. Substances present in the bowel become more concentrated as the faecal stream move slowly towards the distal portion, because the matter gets progressively dehydrated. It is tempting to speculate that carcinogens present in the bowel would be more concentrated towards the distal part and the period of contact would be lengthened if there was stasis. Two thirds of the malignant neoplasms of the large bowel occur in this distal portion. It has been argued that infrequent occurrence of 


\section{International Journal of Science and Research (IJSR) \\ ISSN (Online): 2319-7064 \\ Index Copernicus Value (2013): 6.14 | Impact Factor (2015): 6.391}

cancer in the large intestine in some parts of the African and other countries like India may be due to at least in part to the liberal diet of green vegetables etc., which leaves behind large residue, plus the habit of increased bowel movements possibly due to chronic infections from tuberculosis, intestinal parasites and amoebic dysentery. It is possible that the same factors are responsible for the smaller number of cases of cancer of the colon in our country and in this region. Adenocarcinoma 179 cases $86.89 \%$ was the commonest histological type of lesion in the large intestine followed by, carcinoid 9 cases $4.36 \%$, GISTS were 5 cases $2.43 \%$ and 3 cases of lymphoma $1.45 \%$ table 1 . The incidence and localization of primary GI lymphomas varies worldwide. The GI lymphomas in adults arise predominantly in the stomach whereas intestinal malignant lymphomas are rather infrequent and show no site prevalence in the bowel. Accurate histopathology of malignant tumours of colorectum is essential to plan the mode of treatment and to assess the prognosis. In the case of adenocarcinoma, mucin producing form has been observed to have worse prognosis because of extensive spread.

\section{Conclusion}

206 malignant tumours of large intestine including caecum colon and rectum during the period2007-2015 in the department of pathology RIMS Kadapa are reviewed and their prevalence of site distribution and relationship in age and sex and histopathology characteristics studied. Adenocarcinoma was the commonest type. The peak incidence is noted in the age group of 41-60 and male to female ratio of 2:1 and rectum is the commonest site in the large intestine.

\section{Future Scope}

Colorectal cancer is the second most common GIT malignancies. Its prevention is important. Future studies are needed to enlighten on the prevention, newer methods of diagnosis and treatment of colorectal cancer from Indian point of view.

\section{References}

[1] Boyle P, et al, Descriptive epidemiology of colorectal cancer. Int J Cancer, 1985,36:9-18.

[2] weisburger JH. Causes, relevant mechanisms and prevention of large bowel cancer. Semin oncol 1991, 18:316-336.

[3] Levin B. Nurition and colorectal cancer. Cancer 1992,70:1723-1726.

[4] Lynch HT, Hereditary colorectal cancer.N Eng J Med 2003,348:919-932.

[5] Jass JR, 1991 Subsite distribution and incidence of colorectal cancer in Newzealand. Diseases of colon and rectum 34:56-59.

[6] Peltomaki P Genetic mapping of a locus predisposing to human colorectal cancer. Science 1993, 260:810-812.

[7] Hill MJ. Bacteria and the etiology of colonic cancer. Cancer 1974,34:815-818.

[8] Toribara NW, Sleisenger MH. Screening for colorectal cancer. N Eng J Med 1995, 332:861-867.
[9] Selby JV, Friedman GD. A case control study of screening sigmoidoscopy and mortality form colorectal cancer. N Eng J Med 1992, 326:653-657.

[10] cooper HS, Slemmer JR. Surgical pathology of carcinoma of the colon and rectum. Semin Oncol 1991, $18: 367-380)^{10}$.

[11] Shousha S. Paneth cell rich papillary adenocaracinoma and a mucoid adenocarcinoma occuring synchronously in colon. A light and electron microscopic study. Histopathology 1979, 3: 489-501.

[12] Rodrigues NR et al., p53 Mutations in colorectal cancer. Proc Nat Aced Sci.USA 87:7555-59, 1990.

[13] Newland RC , Dent OF, Lyttle MN, Chapuis PH, Bokey EL. Pathologic determinants of survival associated with colorectal cancer with lymph node metastases. Cancer 1994, 73:2076-2082.

[14] O'connell JB et al; colon cancer survival rates with new American Joint Committee on cancer sixth edition staging. J Natl Cancer Inst96:1420,2004

[15] Morson BC et al. Pathology of anal cancer Proc. R.Soc. Med.61:623-626, 1968.

[16] Kohno S, Ohshima K, Yoneda S, Kodama T, Kikuchi M. Clinicopathological analysis of 143 primary malignant lymphomas in small and large intestines based on the new WHO classification. Histopathology 2003, 43:135-143.

[17] Miettinen $M$ et al gastrointestinal tumours in the Rectum. Am J Surg pathol 2001, 25:1121-1133.

[18]Hock YL et al Mixed adenocarcinoma/carcinoid tumourof large bowel in a patient with crohn's disease. J Clin Pathol 1993, 46: 183-185.

[19] Federspiel BH, et al. Rectal and colonic carcinoids. A clinicopathologic study of 84 cases. Cancer 1990, 65: 135-140.

[20] Sobin LH et al., Prostatic acid phosphatise activity in caracinoid tumours, cancer 1986, 58: 136-138.

[21] O'Brian DS, Dayal Y et al., rectal carcinoids as tumours of the hindgut endocrine cells. A morphological and immnohistochemical analysis. Am J Surg Pathol 1982, 6: 131-142.

[22] Winder EL, Reddy BS 1975, Epidemiology of cancer of the large bowel Dig.Dis 19: 937-946.

[23] Jussawala DJ and Bhansali SK, cancer in the tropics A comparative study with special reference to India, Ind J. Cancer 6:1-26, 1969.

[24] Pay master JC et al. Cancer in gastrointestinal tract in India. Epidemiological study. Cancer 1968, 2:279-288.

Table 1: malignant tumours of colo-rectum histopathology

\begin{tabular}{|l|l|l|}
\hline types \\
\hline Histopathology type & Number & Percentage \\
\hline Adenocarcinoma & 179 & 86.89 \\
\hline Lymphoma & 003 & 01.45 \\
\hline Carcinoid & 009 & 04.36 \\
\hline Squamous cell carcinoma & 002 & 00.98 \\
\hline Melano carcinoma & 003 & 01.45 \\
\hline Cloacogenic carcinoma & 002 & 00.98 \\
\hline Basisquamous carcinoma & 001 & 00.48 \\
\hline $\begin{array}{l}\text { Leiomyosarcoma } \\
\text { carcinosarcoma }\end{array}$ & 005 & 02.43 \\
\hline Total & 002 & 00.98 \\
\hline
\end{tabular}




\section{International Journal of Science and Research (IJSR) \\ ISSN (Online): 2319-7064}

Index Copernicus Value (2013): 6.14 | Impact Factor (2015): 6.391

Table 2: Age and Sex distribution of malignant tumours of colon-rectum

\begin{tabular}{|l|l|l|l|}
\hline Age & Male & Female & Total \\
$01-20$ & 007 & 001 & 008 \\
$21-30$ & 010 & 004 & 014 \\
$31-40$ & 024 & 014 & 038 \\
$41-50$ & 032 & 020 & 052 \\
$51-60$ & 029 & 016 & 045 \\
$61-70$ & 030 & 010 & 040 \\
$71-80$ & 006 & 002 & 008 \\
$81-90$ & 001 & 000 & 001 \\
Total & 139 & 067 & 206 \\
\hline
\end{tabular}

Table 3: Segmental distribution of Malignant tumour of colon and rectum

\begin{tabular}{|c|c|c|}
\hline Site & Number & Percentage \\
Caecum & 14 & 1.45 \\
Colon & 75 & 7.75 \\
Rectum & 117 & 12.09 \\
Total & 206 & 21.28 \\
\hline
\end{tabular}

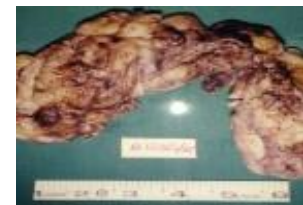

Figure 1: AC sigmoid colon

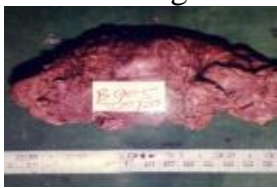

Figure 2: GIST rectum

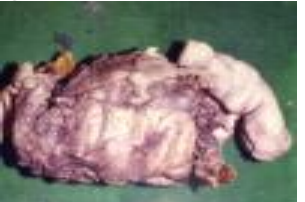

Figure 3: Carcinoid colon

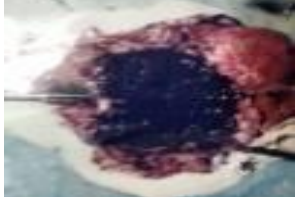

Figure 4: Melanoma of colon

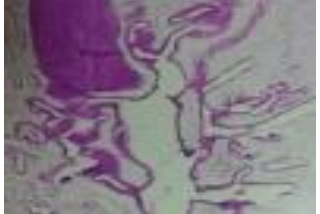

Figure 5: Mucoid AC PAS-5X

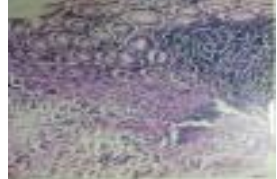

Figure 6: Carcinoid colon HE-5X

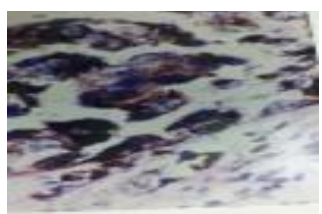

Figure 7: Melanoma colon HE40x

\section{Author Profile}

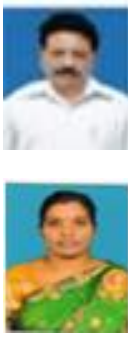

Dr. Y. Subrahmanyam, MD, Associate professor, Department of Pathology, RIMS- Kadapa \& Ongole, India

Dr. K. Suneetha, MD, Assistant Professor, Department of Pathology, RIMS-Ongole, A.P., India 